\title{
An investigation of the effect of different aggregate types on concrete properties with thin section and nondestructive methods
}

\author{
Kadir Güçlüer \\ Department of Construction, Vocational Schools of Technical Science, Adiyaman University, Adiyaman, Turkey \\ kgucluer@adiyaman.edu.tr
}

Submitted: $16 / 02 / 2020$

Revised: 17/01/2021

Accepted: 20/02/2021

\begin{abstract}
Concrete is the most important material in construction industry. Aggregate is one of the most important components of concrete, which consists of many different components. In this study, concrete of constant water/cement ratio was produced by using different types of aggregates, and the effect of aggregate on concrete properties was investigated. After determining the physical properties of the aggregates, the textural properties of the aggregates were investigated with the help of image analysis. Standard water cure was applied to concrete test samples for 7, 28, 90, and 180 days. After the curing process, the physical and mechanical properties of the samples were determined by destructive and nondestructive methods. Thin section samples were taken from hardened concrete samples, and cement aggregate interface investigations were performed under microscope. As a result, it has been determined that aggregate type creates a change in concrete strength, and this situation is related to aggregate properties.
\end{abstract}

Keywords: Concrete; Aggregate; Image analysis; Thin section; Nondestructive methods.

\section{INTRODUCTION}

Concrete is one of the most important building materials of modern building techniques. Technological developments in the cement industry and the widening of the use of concrete materials in engineering applications have led to a deeper understanding of the compositions and properties of these materials (Poole, 2016).

Three important parameters that determine the strength of concrete; aggregate, mortar and interface transition zone (ITZ) properties. The use of aggregates with different textural properties and mineralogy in concretes with the same cement mortar phase may cause different strength values of the concrete (Larrad and Belloc, 1997; Wu et al., 2001). However, another important parameter is the cement paste-aggregate interface transition zone. The strong adherence of cement paste and aggregate affects the strengthening of the interface transition zone and the compressive strength of the concrete. At points where cement paste-aggregate adherence is weak, deformation of concrete under load begins with the formation of cracks in the interface transition area. Crack: since it is the weakest phase, it starts at the interface and continues with the cement matrix. Then, in the phase where the aggregate is strong, the crack deviates and continues around the aggregate. Thus, the broken surface existing in the concrete becomes more curlier (Vishalakshi et al., 2018).

Aggregate covers approximately $70-80 \%$ of the volume in the concrete composition. This affects all properties of concrete, especially its strength (Neville, 2011). Thus, it is estimated that the aggregates used will have a significant effect on the concrete properties (Thomas and Folliard, 2007). Aggregate type is very important for desired quality in 
concrete. The use of aggregates of different textural properties together with cement of the same quality may make a difference in concrete properties (Petrounias et al., 2018; Yilmaz and Turul, 2012).

Aggregates can affect all properties of concrete, as well as limit the strength of concrete (Erdoğan, 2015; Alexander and Mindess, 2010). There are different studies on this subject in the literature. Kim et al. (2019) found that the use of aggregates of different origins affects the strength of concrete. Netinger et al. (2011) reported that the high temperature behavior of concrete also changed due to the use of different types of aggregates in their experimental work. Ghorbani et al. (2019) found that the freeze-thaw resistance of the concretes made with different aggregate sizes and different types of aggregates varies depending on the aggregate type. Yoon et al. (2015) observed that the load carrying capacity of concretes produced with different types of aggregates changes at different temperature values. Poon and Lam (2008) determined that the physical and mechanical properties of the prefabricated elements produced by different types of aggregates vary depending on the aggregate type.

Nondestructive methods, although usually simple to perform, have the problem that the analysis and interpretation of the test data is difficult because of the complex nature of the concrete. Schmidt rebound hammer and ultrasonic pulse velocity can be applied to give information about voids, cracks, degree of moisture saturation and similar features (John et al., 1998). Image analysis and processing methods provide important advantages in evaluating the performance of concrete, investigating the components based properties, and establishing a relationship between microstructure and other properties. With these methods, which are performed without the need for high-end hardware and software, researchers have the opportunity to quickly examine the component and performance properties of concrete (Özen and Güler, 2014).In this study, after determining the textural properties of the aggregates by image analysis, the effect of different aggregate types on concrete was determined by destructive and nondestructive methods and supported by thin section research with the help of polarizing microscope.

\section{MATERIALS AND METHODS}

CEM I 42 R type Portland cement, which complies with EN 197-1 (2011), was used in this study. Chemical component data of cement, which was obtained according to EN 196-2 (2013), is given in Table 1. The determination of the setting time and density values of cement were made according to EN 196-3 (2016), and the Blaine fineness determination was made according to EN 196-6 (2010), and the data obtained are given in Table 2.

Table 1. Chemical components of cement.

\begin{tabular}{|c|c|c|c|c|c|c|c|c|}
\hline Oxide (\%) & $\mathbf{C a O}$ & $\mathbf{S i O}_{2}$ & $\mathbf{F e}_{2} \mathbf{O}_{\mathbf{3}}$ & $\mathbf{A l}_{\mathbf{2}} \mathbf{O}_{3}$ & $\mathbf{M g O}$ & $\mathbf{S O}_{3}$ & $\mathbf{K}_{2} \mathbf{O}$ & $\mathbf{L O I}$ \\
\hline Cement & 62,63 & 19,29 & 4,25 & 3,88 & 3,42 & 2,58 & 0,34 & 2,86 \\
\hline
\end{tabular}

Table 2. Physical properties of cement.

\begin{tabular}{|c|l|c|}
\hline \multicolumn{2}{|c|}{ Properties } & Results \\
\hline \multicolumn{2}{|c|}{ Specific gravity $\left(\mathrm{g} / \mathrm{cm}^{3}\right)$} & 3.09 \\
\hline \multirow{2}{*}{ Setting time } & Start $($ minute $)$ & 125 \\
\cline { 2 - 3 } & Finish (minute) & 190 \\
\hline \multicolumn{2}{|c|}{ Blaine fineness $\left(\mathrm{cm}^{2} / \mathrm{g}\right)$} & 3420 \\
\hline
\end{tabular}

Three different types of aggregates were used in concrete production. Two of these aggregates are crushed stone, and one is natural river aggregate. Concretes produced from crushed stone aggregates are coded with CS1 and CS2, and concretes produced from natural river aggregates are coded with NA. CS1 and CS2 crushed stone aggregates were obtained from crushers with vertical shaft and tertiary jaw structure. The aggregate used in concrete mixtures (CS1, 
CS2, NA) has a maximum grain size of $22 \mathrm{~mm}$. The water absorption capacity and specific gravity of the aggregates were determined according to EN 1097-6 (2013) (Table 3) and aggregate granulometry was determined according to EN 12620 (2008) (Fig. 1).

Table 3. Aggregate physical properties.

\begin{tabular}{|l|l|c|c|c|}
\hline \multicolumn{2}{|c|}{ Specific gravity $\left(\mathbf{g} / \mathbf{c m}^{\mathbf{3}}\right)$} & NA & CS1 & CS2 \\
\hline & Fine (0-5 $\mathbf{~ m m )}$ & 2.52 & 2.42 & 2.41 \\
\hline Coarse (5-12 $\mathbf{~ m m )}$ & 2,52 & 2.44 & 2.52 \\
\hline Coarse (12-22 $\mathbf{~ m m ) ~}$ & 2.50 & 2.49 & 2.58 \\
\hline \multicolumn{2}{|c|}{ Water absorption (\%) } & 2.48 & 4.47 & 5.00 \\
\hline
\end{tabular}
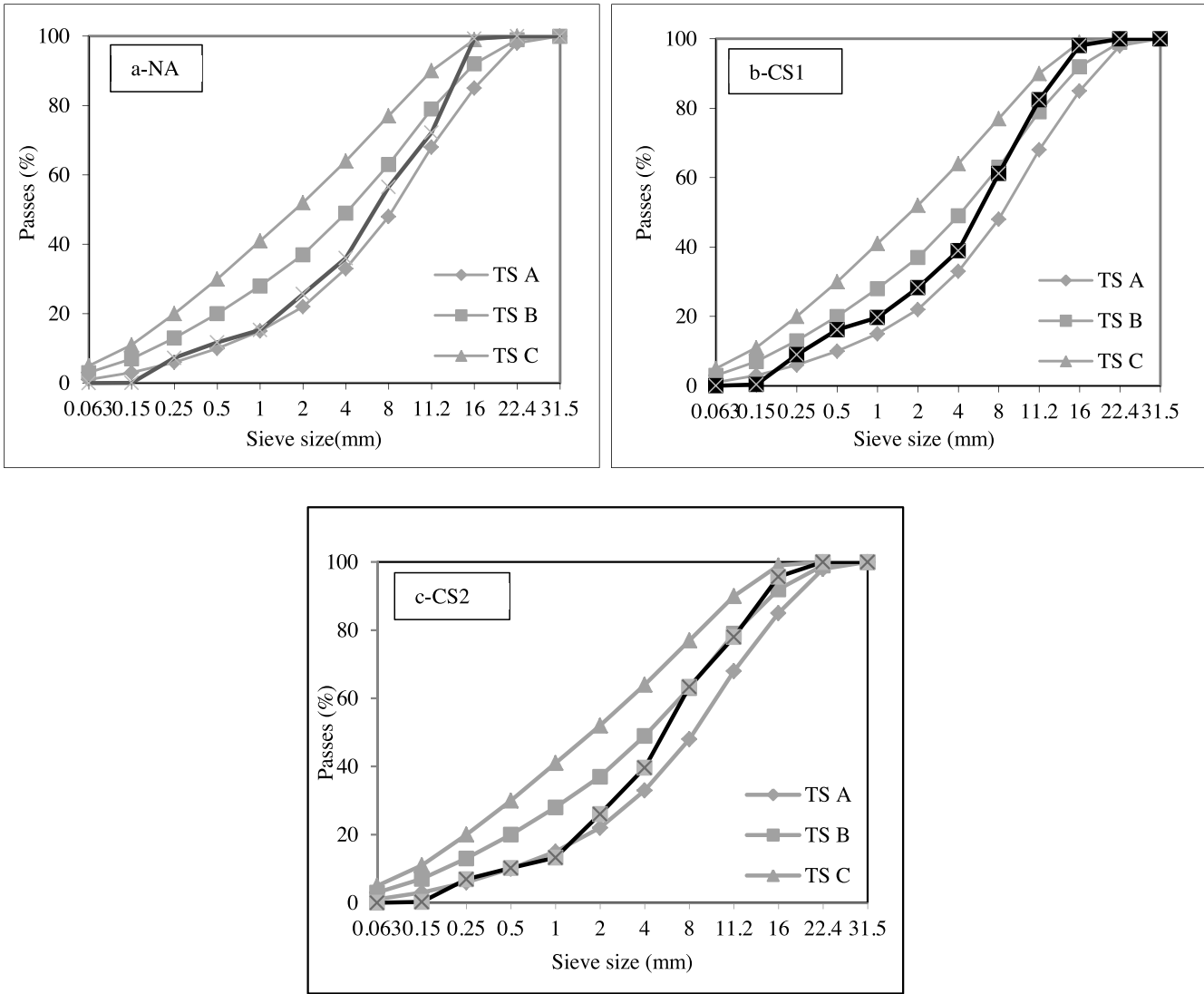

Figure 1. Granulometry of aggregates: (a) NA, (b) CS1 and (c) CS2.

Mixing ratios have been established depending on the absolute volume method specified in TS 802 (2009). Mixing ratios are given in Table 4. NA, CS1 and CS2 series are produced from NA, CS1 and CS2 aggregates. Concrete mixes are based on $\mathrm{C} 25$ concrete class. In order to carry out hardened concrete experiments, fresh concrete was placed in standard cube samples with a $15 \mathrm{~cm}$ edge. Table type vibrator machine was used during the placement of fresh concrete into cube samples (EN 12350-2, 2009). The test samples were kept in the cure pool at an average temperature of 20 degrees for 7, 28, 90 and 180 days. To measure the mechanical properties, three samples were used for each day of the series. 
Table 4. Mixture ratio of 1 cubic meter $\left(\mathrm{kg} / \mathrm{m}^{3}\right)$.

\begin{tabular}{|c|c|c|c|c|c|}
\hline Series & $\begin{array}{c}\text { Fine Aggregate } \\
\mathbf{( 0 - 5} \mathbf{~ m m})\end{array}$ & $\begin{array}{c}\text { Coarse Aggregate } \\
\mathbf{( 5 - 1 2} \mathbf{~ m m})\end{array}$ & $\begin{array}{c}\text { Coarse Aggregate } \\
\mathbf{( 1 2 - 2 2} \mathbf{~ m m})\end{array}$ & Cement & Water \\
\hline NA & 668 & 618 & 444 & 371 & 204 \\
\hline CS1 & 692 & 668 & 324 & 371 & 204 \\
\hline CS2 & 722 & 555 & 538 & 371 & 204 \\
\hline
\end{tabular}

\section{EXPERIMENTAL APPLICATIONS}

Compressive strength (CS) tests were performed according to EN 12390-3 (2009) standard and ultrasonic pulse velocity (UPV) measurements were performed according to ASTM C 597 (1998) standard. Surface hardness measurement with Schmidt hammer rebound was carried out according to ASTM C 805-08 (2008). The surface hardness measurement with Schmidt hammer is used to determine the homogeneity of concrete and compare the concrete with each other in samples with curing conditions of 28, 90 and 180 days.

\section{IMAGE ANALYSIS METHODS}

Photographs of the aggregate samples taken from the aggregates brought to ideal granulometry were taken using daylight (Fig. 2(a)). Image analysis of the photos was carried out with the help of Image Pro-Plus 6.0 program (Fig. 2(b)). Textural properties of aggregates were determined with the help of image processing after this process. Textural properties of the determined aggregate are listed in Table 5.

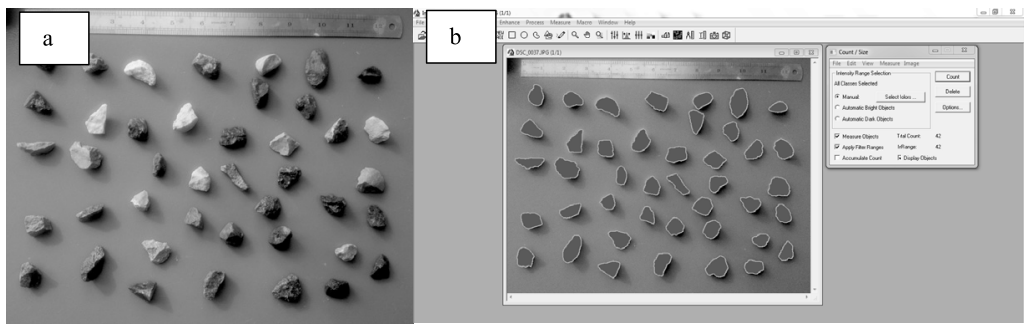

Figure 2. Image analysis processing: (a) aggregates, (b) image analysis.

\section{AGGREGATE SURFACE ROUGHNESS INVESTIGATIONS}

Mitutoyo CV-2100 device was used for aggregate surface roughness measurements. (Fig. 3) In order to determine aggregate surface roughness, 15 aggregate samples were used for each aggregate type (Fig. 3).
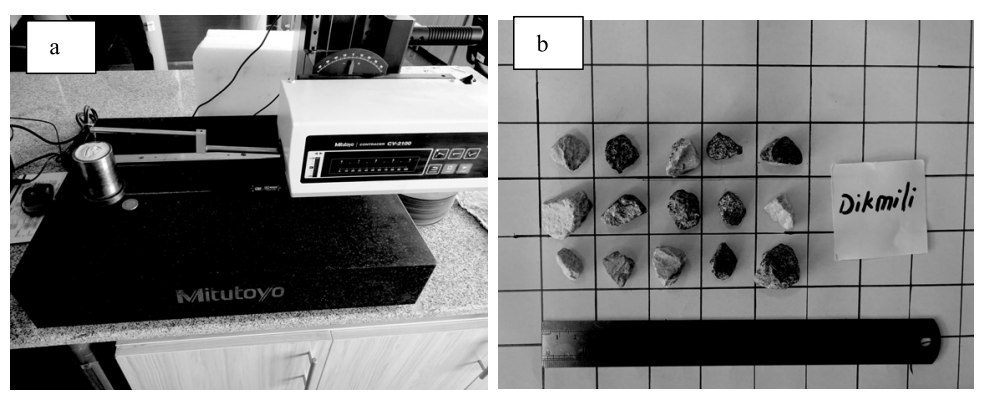

Figure 3. Determination of surface roughness: (a) surface roughness machine, (b) aggregate samples. 


\section{THIN SECTION APPLICATION}

Thin section studies were applied on samples extracted from concrete samples of 28 days. Concrete cube samples with $15 \mathrm{~cm}$ sides were first divided into two with the help of a head cutting machine. The samples, whose homogeneity did not deteriorate, were cut into small pieces and then adhered to the thin section slide and thinned to $0.1 \mathrm{~mm}$ thickness. They were then examined with a polarizing microscope (Fig. 4).

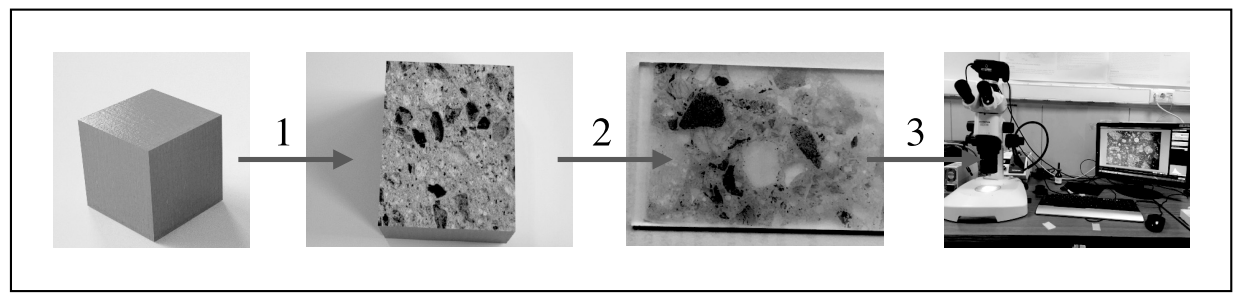

Figure 4. Thin section investigation.

\section{IMAGE ANALYSIS RESULTS}

Textural property data of aggregates obtained by using image analysis method are given in Table 5. Area refers to aggregate area, length and width refers to aggregate length and width. Aspect ratio is one of the most important textural properties of aggregates. Roundness can also be described as a textural properties. Roundness value gets closer to 1, the sphericity becomes perfect, as the value decreases, the aggregate shape moves away from the sphericity (Kahraman et al., 2008). In this sense, the sphericity of the NA aggregate is larger than the two aggregates CS1 and CS2.

Table 5. Aggregate textural properties results.

\begin{tabular}{|c|c|c|c|c|c|}
\hline Aggregate & $\begin{array}{c}\text { Average of } \\
\text { Area }\end{array}$ & $\begin{array}{c}\text { Average of } \\
\text { Aspect Ratio }\end{array}$ & $\begin{array}{c}\text { Average of } \\
\text { Roundness }\end{array}$ & $\begin{array}{c}\text { Average of Size } \\
\text { (Length) }\end{array}$ & $\begin{array}{c}\text { Average of Size } \\
\text { (Width) }\end{array}$ \\
\hline NA & 0.72 & 1.42 & 1.17 & 1.12 & 0.81 \\
\hline CS1 & 0.40 & 1.38 & 1.27 & 0.84 & 0.63 \\
\hline CS2 & 0.48 & 1.49 & 1.33 & 0.97 & 0.69 \\
\hline
\end{tabular}

\section{SURFACE ROUGHNESS RESULTS}

The roughness is defined as the irregular short wavelength length that results from, for example, moving from one end to the other. The term Average Roughness $\left(R_{a}\right)$ value is a term used to describe irregularities in the surface area but excludes waviness and formation errors (Çalışkan and Karıhaloo, 2004). Findings of $R_{a}$ value of aggregates, which were used in the series NA, CS1, and CS2, are given in the Table 6. The highest surface roughness value was determined in CS1 aggregate. Surface roughness of CS2 aggregate is lower than CS1. The lowest surface roughness value was determined in NA aggregate.

Table 6. Surface roughness findings of aggregates.

\begin{tabular}{|c|c|c|c|}
\hline Aggregate & NA & CS1 & CS2 \\
\hline Average $\mathbf{R}_{\mathrm{a}}(\boldsymbol{\mu} \mathrm{m})$ & 2.01 & 17.30 & 10.44 \\
\hline
\end{tabular}




\section{COMPRESSIVE STRENGTH RESULTS}

The compressive strength values of 7, 28, 90 and 180 days of concrete test samples produced by using 3 different types of aggregates are given in Figure 5.

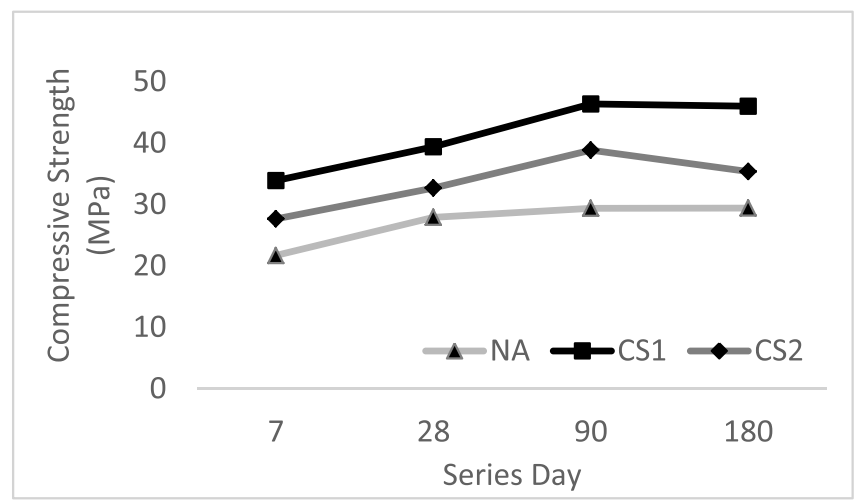

Figure 5. Compressive strength results.

The highest compressive strength values were determined for all curing times in the CS1 series. The lowest compressive strength values were determined in NA series. Compared to NA series, the compressive strength values of CS1 series were increased by $56.22 \%$ for 7 days, $41.21 \%$ for 28 days, $57.93 \%$ for 90 days and $56.34 \%$ for 180 days. Concrete test samples produced with all three aggregate types have reached the compressive strength value of the targeted C25 concrete class. It can be said that the grading and mixing ratios used in this direction have achieved their purpose. The compressive strength of concretes produced with crushed stone aggregate (CS1-CS2) is higher than that of concretes produced with natural aggregate (NA). One of the parameters affecting the adherence between cement paste and aggregate is the textural properties of the aggregate. Since the increase in aggregate surface roughness improves adherence, it can increase the compressive strength (Demirboğa et al., 2004). The fact that the CS1 aggregate has the highest roughness value and that the compressive strength of the concrete produced with this aggregate is the highest is also confirmed by this information.

\section{ULTRASONIC PULSE VELOCITY RESULTS}

The test results carried out according to ASTM C 597 are given in Fig. 6. The highest UPV values were found in $\mathrm{CS} 1$ series and the lowest values were found in NA series in all day periods.

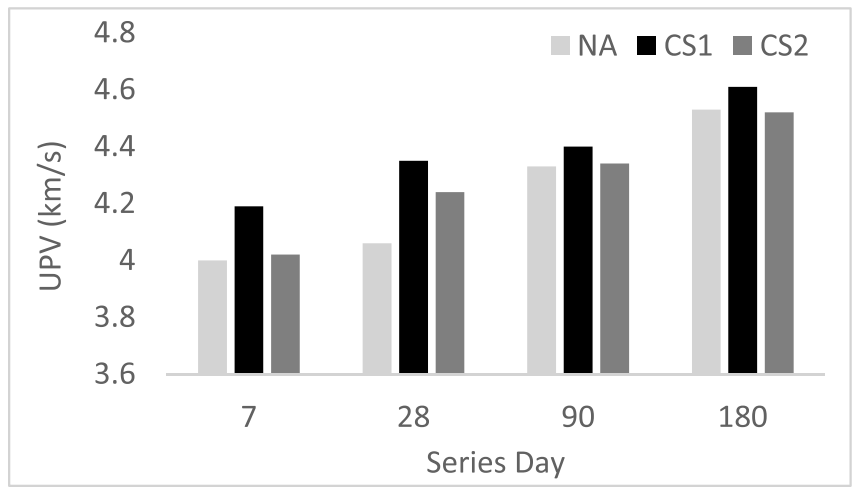

Figure 6. Ultrasonic pulse velocity results. 
It is stated that in the literature there is a direct relationship between compressive strength and ultrasonic pulse velocity (Mahta and Monteiro, 2006). The correlation value was found to be $\mathrm{R}^{2}=0.90$ in the NA series, $\mathrm{R}^{2}=0.74$ in the CS1 series, and $\mathrm{R}^{2}=0.81$ in the CS2 series (Fig. 7). The data obtained are consistent with the literature.

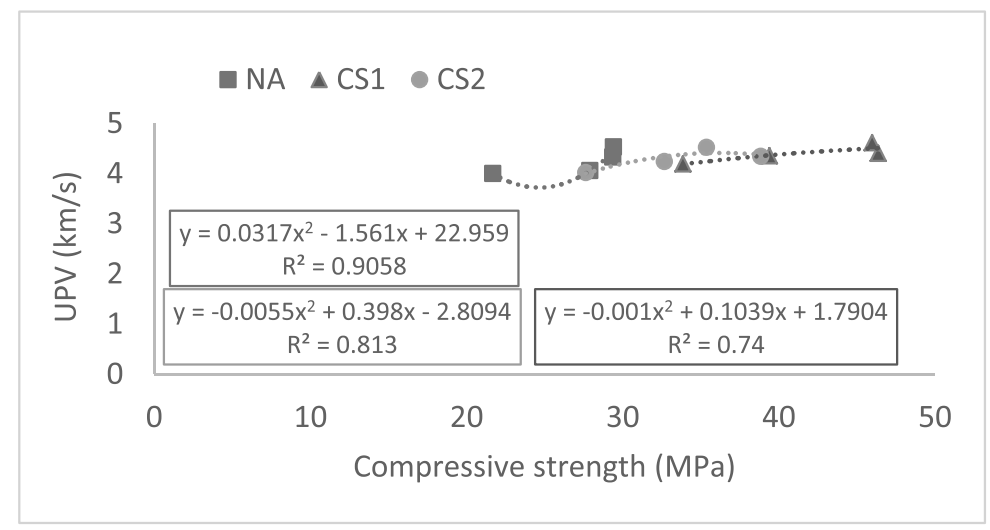

Figure 7. Correlation between UPV and compressive strength results.

\section{SCHMIDT HAMMER REBOUND RESULTS}

Nondestructive (NDT) measurement methods can be used to determine the quality of concrete. The Schmidt hammer technique is one of the most preferred of these measurement methods. (Szilágyi et al., 2011). Schmidt hammer rebound readings were performed on cured experimental samples for 28, 90, and 180 days. The results for Schmidt hammer rebound values are given in Figure 8. The highest values were determined in the series produced with CS1 aggregate. The lowest values were obtained in the series produced with NA aggregate. It is thought that there is a direct relationship between Schmidt hammer and compressive strength. The highest values obtained in compressive strengths were obtained in Schmidt hammer and UPV values. Strengthening of the cement-aggregate intermediate phase can be shown as an increase in concrete hardness and compressive strength.

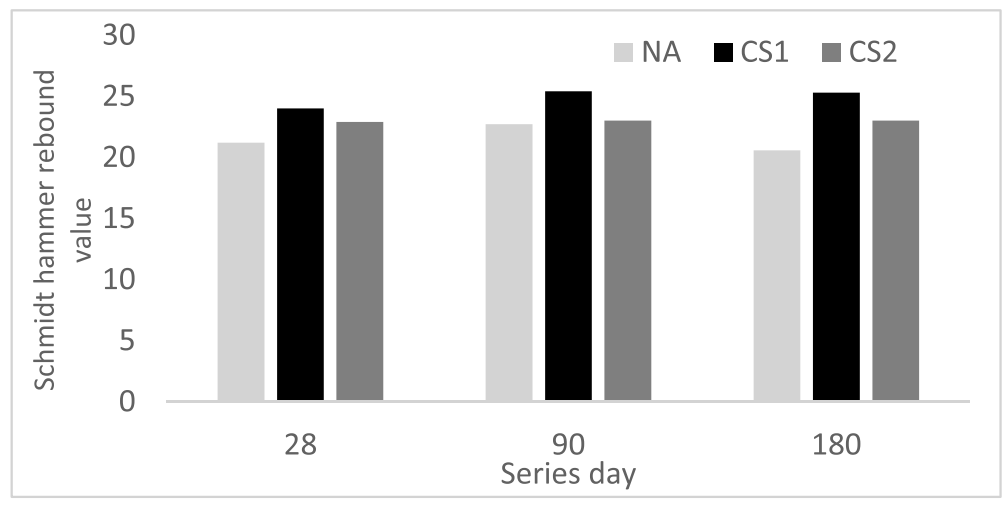

Figure 8. Schmidt hammer rebound results.

\section{THIN SECTION INVESTIGATION RESULTS}

Thin section examination of concretes produced from three different types of fine and coarse aggregates was carried out with the help of polarizing microscope. Aggregate cement paste adherence of the samples taken from 28 days hardened concrete samples was examined and compared between each other (Fig. 9). 

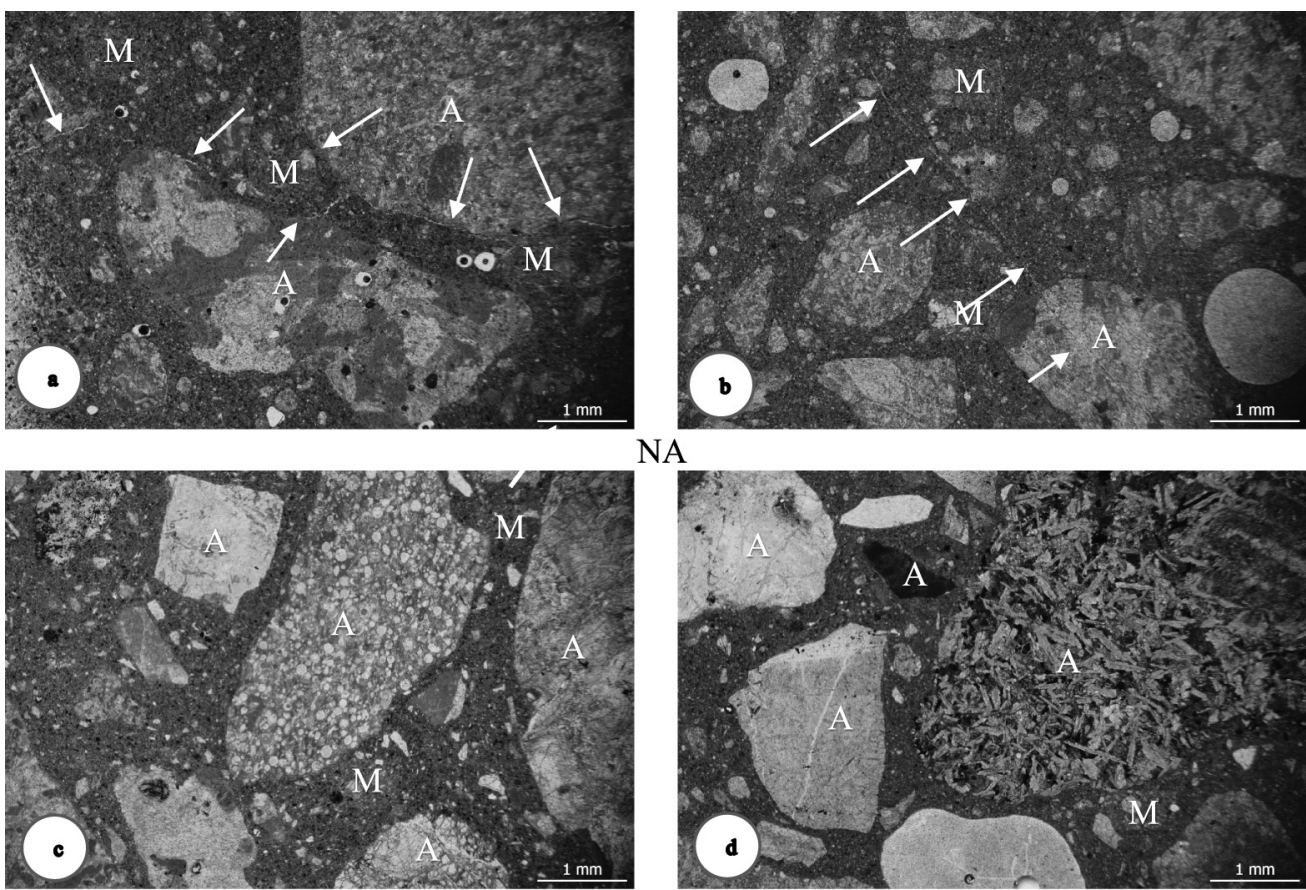

NA

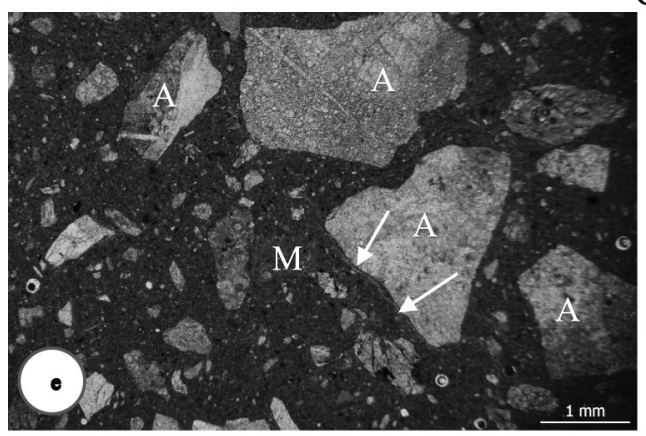

CS1
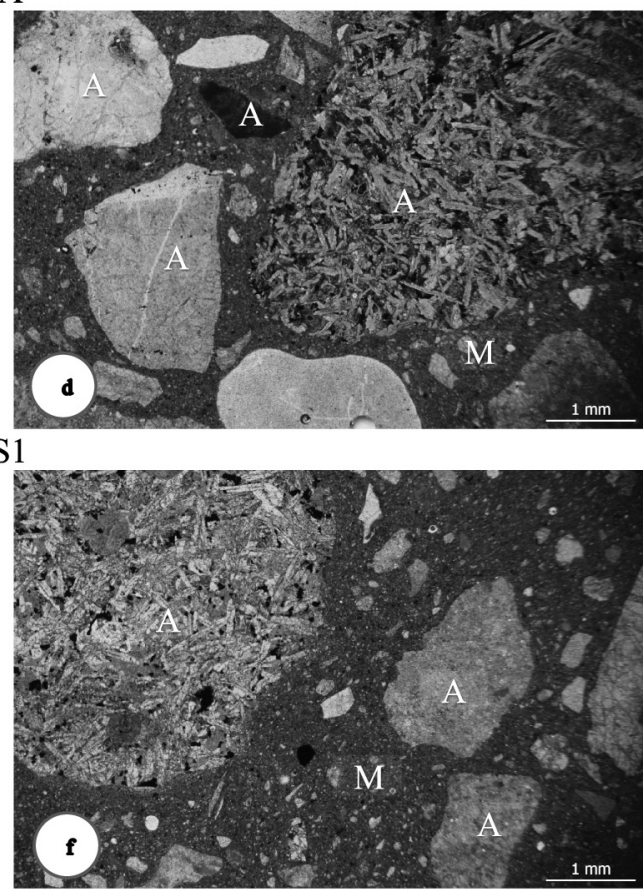

CS2

Figure 9. Thin section investigations: (a,b) NA, (c,d) CS1, (e,f) CS2 (A: Aggregate, M: Matrix).

In Figure $9 \mathrm{a}$ and $\mathrm{b}$, thin section images obtained from concrete produced with natural aggregate are shown. It is clearly seen that natural aggregates are more spherical than crushed stone aggregates listed in Figure 9 c-e. Cracks seen in the matrix structure of concretes produced with natural aggregates are quite distinct and progress by following the cement paste-aggregate interface area. This situation is thought to be related to the aggregate surface roughness and the data obtained from the compressive strength tests are considered to support this situation. In Figure $9 \mathrm{~b}$-e, in the thin sections of concretes produced with crushed stone aggregates, aggregates with less sphericity than normal aggregates are clearly seen in a dense matrix. Significant crack formation within the structure of crushed stone aggregates is much lower than concrete produced with normal aggregate. In fact, no significant crack formation was observed in concretes produced with CS1 aggregate. It can be said that the highest compressive strength of the concrete produced with CS1 aggregate is affected by the surface roughness of the aggregates, and the aggregate surface roughness causes an increase in strength by strengthening the cement paste-aggregate interface area. Although crack formation was observed in concretes produced with CS2 aggregate, it was observed that crack formation remained weak compared to concrete produced with normal aggregate. 


\section{CONCLUSION}

As a result of the experimental study investigating the effect of aggregate type on concrete samples produced with different types of aggregate, the following information was obtained:

- The highest compressive strength values were observed in concretes produced with crushed stone aggregate. The compressive strength values of concretes produced with natural aggregate are lower. The highest compressive strength values were determined in concretes produced with CS1 aggregate.

- The matrix of concretes produced with crushed aggregate is denser. Crack formation observed in the matrix of concretes produced with natural aggregate is more than the concretes produced with crushed aggregate.

- Aggregate textural properties affect the compressive strength of concrete.

- Schmidt hammer rebound values increase due to increased surface roughness.

- UPV values were increased due to the increase in compressive strength of concrete.

- Concrete compressive strength increases due to the increase of surface roughness value of aggregates.

\section{REFERENCES}

Alexander, M., Mindess, A.S. 2010. Aggregates in concrete, Taylor and Francis.

ASTM C 597-97, 2016. Standard test method for pulse velocity through concrete. ASTM International, West Conshohocken, PA.

ASTM C 805-08, 2018. Standard test method for rebound number of hardened concrete, ASTM International, West Conshohocken, PA.

Çalışkan, S., Karıhaloo, B. 2004. Effect of surface roughness, type and size of model aggregates on the bond strength of aggregate/ mortar interface. Interface Science, 12(4): 361-374.

Demirboğa, R., Türkmen, İ. \& Karakoç, M.B. 2004. Relationship between ultrasonic velocity and compressive strength for high-volume mineral-admixtured concrete. Cement and Concrete Research, 34(12): 2329-2336.

EN 196-2, 2013. Method of testing cement-Part 2: Chemical analysis of cement. European Standards.

EN 196-3, 2016. Methods of testing cement-Part 3: Determination of setting times and soundness. European Standards.

EN 196-6, 2011. Methods of testing cement-Part 6: Determination of fineness. European Standards.

EN 197-1, 2011. Cement - Part 1: Composition, specifications and conformity criteria for common cements. European Standards.

EN 1097-6, 2013. Tests for mechanical and physical properties of aggregates. Determination of particle density and water absorption. European Standards.

EN 12620, 2008. Aggregates for concrete. European Standards.

EN 12350-2, 2009. Testing fresh concrete - Part 2: Slump-test. European Standards.

EN 12390-3, 2009. Testing hardened concrete - Part 3: Compressive strength of test specimens. European Standards.

Erdoğan, T. 2015. Beton, $5^{\text {th }}$ Edition, METU Press.

Ghorbania, S., Sharifia, S., Ghorbania, S., Tamb, V.W., Britoc, J.D. \& Kurda, R. 2019. Effect of crushed concrete waste's maximum size as partial replacement of natural coarse aggregate on the mechanical and durability properties of concrete. Resources, Conservation \& Recycling 149(November): 664-673.

John, D.A., Poole, B.A. \& Sims, I. 1998. Concrete Petrography: A Handbook of investigate techniques, Arnold.

Kahraman, S., Alber, M., Fener, M. \& Gunaydin, O. 2008. Evaluating the geomechanical properties of Misis fault breccia (Turkey). International Journal of Rock Mechanics and Mining Science, 45(8):1469-1479.

Kim, S.S, Qudoss, A., Jakhrani, S.H., Lee, J.B. \& Kim, G.H. 2019. Influence of coarse aggregates and silica fume on the mechanical properties, durability, and microstructure of concrete. Materials 12: 3324. 
Larrad, F., Belloc, A. 1997. The influence of aggregate on the compressive strength of normal and high-strength concrete. ACI Materials Journal, 94(5): 417-425.

Mehta, P.K., Monteiro, P.J.M. 2006. Concrete Microstructure, Properties and Materials, Third Edition, Mc Graw Hill Education.

Neville, A.M. 2011. Properties of concrete, $5^{\text {th }}$ Edition, Pearson Education Limited.

Netinger, I., Kesegic, I. \& Guljas, I. 2011. The effect of high temperatures on the mechanical properties of concrete made with different types of aggregates. Fire Safety Journal, 46(7): 425-430.

Özen, M., Güler, M. 2014. Assessment of optimum threshold and particle shape parameter for the image analysis of aggregate size distribution of concrete sections, Optics and Lasers in Engineering 53 (February) 122-132.

Petrounias, P., Giannakopoulou, P.P., Rogkala, A., Stamatis, P.M., Tsikouras, B., Papoulis, D., Lampropoulou, P. \& Hatzipanagiotou, K. 2018. The influence of alteration of aggregates on the quality of the concrete: A case study from serpentinites and andesites from central Macedonia (North Greece). Geosciences, 8(4): 115.

Poole, B.A., Sims, I. 2016. Concrete petrography, Second Edition, CRC Press.

Poon, C.S., Lam, C.S. 2008. The effect of aggregate-to-cement ratio and types of aggregates on the properties of pre-cast concrete blocks. Cement \& Concrete Composites, 30(4):283-289.

Szilágyi, K., Borosnyói, A. \& Zsigovics, I. 2011. Rebound surface hardness of concrete: introduction of an empirical constitutive model. Construction and Building Materials, 25(5): 2480-2487.

Thomas, M.D.A., Folliard, K.J. 2007. Concrete aggregates and the durability of concrete. Durability of Concrete and Cement Composites, p.247-281, CRC Press.

TS 802, 2009. Beton Karışım Tasarımı Hesap Esasları, Turkish Standards.

Vishalakshi, K.P., Revathi, V. \& Sivamurthy, R.S. 2018. Effect of type of coarse aggregate on the strength properties and fracture energy of normal and high strength concrete. Engineering Fracture Mechanics 194(February): 52-60.

Yilmaz, M., Turul, A. 2012. The effects of different sandstone aggregates on concrete strength. Construction and Building Materials 35(October): 294-303.

Yoon, M., Kim, G., Choe, C.G., Lee, Y. \& Lee, T. 2015. Effect of coarse aggregate type and loading level on the high temperature properties of concrete. Construction and Building Materials 78(March): 26-33. 